\title{
Competências produtivas e visão estratégica: um modelo de gestão interativa
}

\author{
Edson Pacheco Paladinia,**, Fabrícia Gonçalves de Carvalho ${ }^{\mathrm{b}}$ \\ a,*paladini@deps.ufsc.br, UFSC, Brasil \\ bfabriciagc@gmail.com, UFSC, Brasil
}

\begin{abstract}
Resumo
Partindo da distinção conceitual entre decisão estratégica e ação estratégica, apresenta-se, aqui, um modelo que, fazendo uso da noção de competências produtivas, gera uma estrutura interativa de agregação dos elementos que compõem o diferencial competitivo de uma organização. 0 objetivo dessa estrutura é definir os meios de atuação da empresa no mercado e, mais em geral, na sociedade como um todo. Para fundamentar o desenvolvimento do modelo proposto foi elaborado um suporte teórico de conceitos, posições e argumentações relativas ao processo de gestão estratégica, nas suas variadas abordagens e distintos enfoques. 0 modelo está em processo de efetiva implantação em uma organização industrial, tendo nela sido utilizadas suas fases básicas na definição do comportamento estratégico da empresa em estudo nos últimos dois anos. A análise conceitual e as lições práticas advindas do processo de implantação efetiva do modelo permitem formular algumas conclusões (gerais e específicas) acerca da proposta aqui descrita.
\end{abstract}

Palavras-chave

Competências produtivas. Visão estratégica. Gestão interativa.

\section{Introdução}

0 presente trabalho objetiva criar meios efetivos para que as organizações viabilizem o seu modelo de gestão estratégica, uma questão crítica pelo seu impacto na sobrevivência dessas organizações. A abordagem prática proposta para tanto consiste na estruturação de um processo interativo em duas dimensões. Na primeira, essa interação ocorre entre os próprios meios e recursos disponíveis na organização, de forma a reforçar potencialidades existentes e transformá-las em diferenciais competitivos; na segunda, busca-se o direcionamento desta ação sinérgica para a criação de padrões individualizados de atendimento a mercados e, mais geral, a toda a sociedade. 0 atendimento ao mercado mantém a empresa hoje, garantindo que ela permaneça viva; a atenção à sociedade amplia suas faixas de atuação, assegurando seu crescimento e, por extensão, seu futuro. Esse movimento de ampliação - do mercado atual para novos mercados - é uma característica essencial da gestão estratégica.
De fato, a gestão estratégica, em geral, é o conjunto de processos gerenciais que visa garantir a sobrevivência da indústria. E por sobreviver não se entenda "manter-se viva", justamente porque esse conceito é insuficiente para preservar viva a organização. Sobreviver, aqui, refere-se a gerar possibilidades para que a empresa não só se mantenha viva, mas, sobretudo, e até para viabilizar o seu futuro, cresça, amplie-se, progrida, enfim, evolua (sobreviver = mais do que viver...).

A visão que mais bem individualiza a gestão estratégica é a que gera um conjunto de ações de mútua reciprocidade entre as características intrínsecas da organização (espaço interno) e o ambiente no qual ela atua (cenários externos). No primeiro caso, inserem-se o processo produtivo, os recursos humanos disponíveis, as estratégias de operação, os bens e serviços gerados, a localização física, a logística etc. No segundo, os elementos mais críticos são mercado consumidor, concorrentes, aspectos ambientais e toda a sociedade. 
A prioridade da gestão estratégica é determinar uma característica própria na atuação da empresa de forma a garantir que bens, serviços e métodos por ela disponibilizados sejam aceitos, desejados e fidelizados pelo mercado. Ou seja, que essa característica seja um diferencial que mantenha a organização no mercado e, principalmente, amplie sua participação nele, pela diversificação das faixas atendidas.

A gênese e a motivação deste trabalho nasceram da observação prática. De fato, desde o primeiro semestre de 2004, alunos de graduação e pós-graduação na área de Engenharia de Produção da Universidade Federal de Santa Catarina têm interagido com organizações produtivas dos setores de bens industriais e de serviços, instaladas em seis estados brasileiros, acompanhando o esforço destas organizações em selecionar as características que possam transformar-se em diferencial competitivo. Ou seja: o empenho dessas organizações em definir um perfil estratégico com base em suas potencialidades e na adequação delas ao mercado e à sociedade. Esse direcionamento empírico, desde sua origem, caracteriza o problema de pesquisa (selecionar quais características apresentam componentes estratégicos entre as potencialidades produtivas da organização) e confere uma delimitação importante ao presente trabalho: a proposta de solução para o problema de definir esse perfil estratégico é fortemente influenciada pela realidade, pelas práticas, pela cultura, pelos processos e pelos próprios mecanismos de atuação das organizações estudadas, que, embora formem um espectro bastante amplo, não são capazes de representar todo o leque de empresas produtivas. De outra parte, a abordagem selecionada, que enfatiza as competências produtivas, e o método proposto, interação entre essas competências, são, também, considerados como delimitações na busca de solução para o problema em questão.

Normalmente, a gestão estratégica é exercida pela alta administração da organização. Isso não significa, contudo, que todas as ações da gestão estratégica sejam desempenhadas nesse nível, que, por analogia e ajuste ao processo de tomada de decisão, costuma ser chamado de nível estratégico. Assim, observa-se que há uma diferença a ser considerada entre ações estratégicas e decisões estratégicas.

0 presente trabalho começa com a análise dessa distinção. Essa discussão permitirá definir como se pode gerar um processo de interação dos elementos da empresa, de modo a direcionar o caráter estratégico de suas decisões com base em competências produtivas disponíveis. Considerando a segunda dimensão acima mencionada, as competências deverão estar focadas no esforço de consolidar posições da organização no mercado (momento atual) e na sociedade (possibilidades de crescimento em termos de novos mercados). 0 esboço metodológico do trabalho compõe o item 3. A seguir, desenvolve-se o suporte teórico necessário para dar sustentação ao modelo proposto, descrito no item 4. 0 item 5 descreve o modelo proposto e, para estudar a viabilidade de sua utilização, um estudo de caso é discutido no item 6 . Um conjunto de conclusões encerra o texto (item 7).

\section{Ações estratégicas e decisões estratégicas}

Nem todas as ações estratégicas são desenvolvidas em nível estratégico. Com efeito, ações estratégicas podem ser criadas em nível operacional quando, por exemplo, a organização dispõe de um processo produtivo diferenciado, que permite gerar, também, produtos diferenciados. Exemplos desta situação são as empresas que possuem equipamentos ou métodos "de ponta" em relação aos concorrentes (foi o caso do primeiro fotógrafo da cidade que se propôs a revelar fotos $3 \times 4$ em uma hora; ou da confeitaria mais popular na cidade, que alcançou essa posição por contratar as doceiras mais conhecidas e famosas do lugar).

Uma ação estratégica de nível tático pode ser constatada quando a organização se diferencia pela elevada qualificação dos seus recursos humanos (caso das empresas de alta tecnologia que investem na produção de softwares, por exemplo). Ou por um processo gerencial que gera índices notáveis de motivação (e, por consequência, de participação) de seu pessoal, o que possibilita contínuas inovações em bens e serviços, sempre a gosto do mercado.

A ação estratégica viabilizada em nível estratégico (caso mais usual) é aquela que envolve decisões mais amplas, de longo alcance e de prazo de execução maior, sempre visando criar referenciais específicos de atuação. São decisões que consideram o ambiente externo da empresa, sobretudo em termos de diferenciação quanto à concorrência. Assim, o lançamento de novos produtos é um exemplo que se insere nesse contexto. Como nos dois primeiros tipos de gestão, também aqui são enfatizados elementos externos à organização.

Alguns traços comuns aos três tipos de ações estratégicas caracterizam com perfeição a própria gestão estratégica da organização. Esses traços são formatados quando se buscam respostas a questões gerais, críticas para a sobrevivência de qualquer empresa, a partir das quais os demais elementos que 
caracterizam cada tipo de ação ficam evidenciados, como se pode ver a seguir:

- Gestão estratégica com base na ação operacional - As questões gerais a responder aqui são: 0 que nós sabemos fazer que os outros (os concorrentes) não sabem? 0 mercado se interessa por isso? Quais nossas deficiências de operação - elas devem ser minimizadas, terceirizadas ou desconsideradas? Esta é a gestão direcionada à eficiência das operações. 0 modelo de gestão da qualidade aqui utilizado é baseado em indicadores in-line; a gestão de processo enfatiza as competências produtivas (capacidade de operação dos equipamentos, por exemplo). Ação diferenciada pela forma como a organização opera equipamentos, operações de processo e materiais.

- Gestão estratégica com base tática - Busca responder questões como: 0 que caracteriza a cultura, o modelo gerencial, a ação dos recursos humanos e as práticas usuais da organização? Tais características configuram elementos de atratividade ao mercado? Quais falhas estruturais, culturais ou comportamentais comprometem a atuação mais efetiva da organização? Trata-se de um modelo de gestão direcionado tanto à eficiência quanto à eficácia das operações. Aqui, a gestão da qualidade emprega indicadores off-line e a gestão de processo enfatiza as competências produtivas (capacidade humana: processos gerenciais, qualificação, níveis de motivação, por exemplo). Ação diferenciada pela forma como a empresa desenvolve seus métodos de trabalho.

- Gestão estratégica com base estratégica Concentra-se em questões como: Que produtos devem ser lançados - coletivizados (alcance de amplas faixas de mercado) ou particularizados (visam segmentos específicos do mercado)? 0 que deve ser considerado no lançamento de um produto novo (exemplos: barrar o crescimento da concorrência, consolidar uma marca, propor uma solução para um momento de crise ou simplesmente inovar)? Essa é a gestão direcionada à eficácia das operações. A gestão da qualidade utiliza, nesse caso, indicadores on-line, e a gestão de processo evidencia as observações do ambiente externo (mercados, tendências sociais, aspectos culturais, legislação, concorrência, características atuais e futuras etc.). Ação diferenciada pela forma como a organização atua.

Não parece viável agir estrategicamente com base em apenas um desses conjuntos de ações. 0 mais comum é privilegiar um conjunto tendo em vista o momento atual, a área de atuação, os objetivos mais imediatos e futuros, a estratégia de operação, as características próprias de cada empresa, entre outros fatores mais pontuais. Mas, como regra geral, a ação gerencial da empresa deve sempre contemplar os três conjuntos de ações.

É nesse ambiente interativo entre os três conjuntos de ações estratégicas que o presente trabalho se insere. Mais exatamente, o modelo aqui proposto trata de decisões estratégicas estruturadas com base em competências produtivas direcionadas para consolidar posições da organização no mercado e na sociedade. Ou seja: trata das competências produtivas em uma visão estratégica, propondo um modelo de gestão que determine a efetiva interação dos três conjuntos de ações estratégicas. Em particular, até por seu papel na abordagem selecionada, o modelo proposto enfatiza dois conjuntos de mecanismos básicos de gestão:

- Gestão estratégica da qualidade, ou o viés estratégico da qualidade no processo gerencial das organizações. Qualidade é, em última análise, o direcionamento das características de operação da empresa para atendimento dos consumidores via atributos de produtos, serviços e métodos. A qualidade, assim, avalia se as competências disponíveis podem (ou não) consolidar posições da organização no mercado e, mais em geral, na própria sociedade. Dessas posições depende a sobrevivência da empresa - por isso, trata-se de uma postura gerencial de características estratégicas.

- Gestão estratégica de processos. Este modelo de gestão prioriza as competências produtivas da capacidade instalada da organização, ou seja, do seu processo produtivo. É estratégico porque essas competências criam o diferencial competitivo da empresa e, portanto, possuem notável impacto na sobrevivência da própria organização, sobretudo frente à ação de seus concorrentes.

\section{Esboço metodológico e delimitações}

Este trabalho tem uma orientação metodológica claramente empírica, típica da engenharia de produção. Sua geração está associada à interação de alunos e professores de cursos de graduação e pós-graduação na área de engenharia de produção com organizações produtivas, tanto do setor industrial quanto de serviços. A observação prática conduziu à definição do problema e, igualmente, à proposta de solução, sob forma de um modelo prático que, por sua vez, foi experimentalmente aplicado como forma de avaliação prévia de sua validade.

Dessa forma, o método de pesquisa aqui empregado é o indutivo, que considera que o conhecimento é fundamentado na experiência, nem sempre tendo em vista princípios ou normas 
preestabelecidos. No raciocínio indutivo, como no presente trabalho, a generalização deriva de observações de casos reais. As constatações particulares conduzem à elaboração de generalizações (GIL, 1999; LAKATOS; MARCONI, 1993). Esse viés pode ser visto no desenvolvimento da proposta, que opera no sentido das particularidades (caso de decisões estratégicas) para as generalizações (modelos de gestão estratégica). Assim, o delineamento metodológico do trabalho está voltado para a busca de resultados consistentes e de efeitos multiplicadores efetivos a partir da observação de problemas reais.

Segundo Gil (2002), a pesquisa exploratória visa proporcionar maior familiaridade com o problema, de modo a torná-lo explícito ou construir hipóteses. Envolve levantamento bibliográfico, entrevistas com pessoas que tiveram experiências práticas com o problema pesquisado e análise de exemplos que estimulem a compreensão. Assume as formas de pesquisas bibliográficas e estudos de caso. Com base nas definições de Gil (2002), o projeto de pesquisa aqui descrito é exploratório e, considerando suas motivações primeiras e o processo de viabilização preliminar de resultados, é classificado como estudo de caso, ao lado do referencial teórico construído para oferecer suporte ao modelo proposto.

Para Bell (2008), pesquisa qualitativa é a que gera uma relação dinâmica entre o mundo real, objetivo, e o sujeito, com sua subjetividade nem sempre podendo ser traduzida em números. A interpretação dos fenômenos e a atribuição de significados são básicas no processo de pesquisa qualitativa. Para Menezes e Silva (2005), o ambiente natural aqui é a fonte direta para coleta de dados, e o pesquisador é o instrumento-chave, privilegiando a abordagem descritiva. 0 processo e seu significado são os focos principais de abordagem. Por essas razões, a abordagem desta pesquisa é a qualitativa.

Quando se analisa o alcance do presente trabalho, as delimitações mais evidentes são: a natureza da proposta de solução para o problema estudado (contaminada pelas ações e situações reais vividas e observadas pelos autores); a seleção da abordagem para estruturar o modelo (competências produtivas que podem transformar-se em diferenciais competitivos) e o método de criar uma interação entre essas competências.

\section{Suporte teórico}

A gestão estratégica tem sido tratada por diferentes autores com diversas ênfases e variadas abordagens. Alguns textos clássicos sobre a questão são o de Ackoff - modelo de planejamento empresarial em uso na década de 70 (ACKOFF, 1978); os de Porter, sobre estratégia competitiva (PORTER, 1991, 1993), além de Tzu e a arte da guerra (CLAVEL, 2000), com a "arte de vencer as guerras". Há visões mais atuais, como a de Albrecht (2001), que propôs um modelo que visa analisar fatos, tendências e forças que podem alterar de forma significativa o futuro de pessoas e organizações. Esse modelo evidencia a necessidade de que a gestão estratégica adote, sempre, uma visão ampla e de médio e longo prazo. Aliás, a preocupação com o futuro é um elemento sempre presente nos estudos de gestão estratégica (ver, por exemplo, GALBRAITH; LAWLER, 2001; GIBSON, 2005; HAMELL; PRAHALAD, 1995; MARCIAL; GRUMBACH, 2002).

Muitos autores desenvolvem suas propostas de gestão estratégica atentando para a figura do empreendedor ou do agente de decisão, o que enfatiza a importância do processo decisório na gestão estratégica (GAJ, 2002; DEGEN, 1999). A visão estratégica das pessoas ("pensamento estratégico") também é um ponto fortemente discutido na literatura técnica (MARKIDES; CUSUMANO, 2002; DIXIT; NELEBUFF, 2006; TELLIS; GOLDER, 2002). Outros autores enfatizam o uso da gestão estratégica apoiada em modelos práticos, simples, voltados para resultados, como Fishmann e Almeida (1990); Bornholdt (1997); Pagnoncelli e Vasconcellos Filho (2001) e Ansoff e McDonnel (2004).

0 papel estratégico da gestão da qualidade, de outra parte, tem sido enfatizado por vários autores, em diferentes situações, como o modelo estratégico para a gestão da qualidade (SRINIDHI, 1998); as bases teóricas para a gestão estratégica da qualidade (JOHANNSEN, 1996); e modelos práticos na área (MADU; KUEl, 2008). Já o papel da qualidade na gestão estratégica também tem sido analisado há muito tempo. Exemplos dessa abordagem podem ser vistos em Beecroft (1999); Dew (2008) e Stahl e Grigsby (2007).

Nichols e Houry (2009) mostram que, em tempos de crise econômica, a ação da gestão da qualidade é crucial para a definição de uma rota de navegação das organizações em meio à tempestade. Por extensão, confere-se à qualidade um papel crítico na condução da organização em um ambiente de turbulência. Wirtz, Mathieu e Schilke (2007) demonstram que a gestão da qualidade interfere na formulação das estratégias de atuação de organizações envolvidas em ambientes que se alteram rapidamente (o que também configura uma crise).

Outrosestudosconsagram elementos estratégicos que envolvem qualidade. É o caso de Pinar e Ozgur (2007), que tratam dos impactos em longo prazo da 
série 1509000 no desempenho das organizações; Guimarães, Staples e McKeen (2007), que analisam como os sistemas de informações para a qualidade são relevantes no comportamento estratégico das organizações; Becton e Schraeder (2009) e Marques (2008), que avaliam a questão sob a ótica dos recursos humanos. Kettunen (2008) desenvolve um modelo que integra a gestão estratégica à garantia da qualidade.

Um método inteligente de conectar gestão da qualidade, gestão de processos e gestão estratégica das organizações é o direcionamento do processo produtivo da empresa para o mercado, sempre tendo em vista as características próprias, lançando-se mão da noção das competências produtivas, ou production competence. Vickery \& Vickery et al. (1993 e 1990) definem production competence como o meio no qual o desempenho da produção auxilia a estratégia de negócios da organização. Pode ser, ainda, o ajuste entre a estratégia da empresa e a estrutura da produção (CHOE; BOOTH; HU, 1997). Aqui, qualidade tem papel crítico, como se percebe. A visão integradora do conceito fica bem definida se for observada a noção de Schmenner e Vastag (2006), segundo a qual o conjunto dos ativos, das capacidades, dos processos organizacionais, dos atributos, das informações, do conhecimento, entre outros, é controlado pela empresa, o que permite a ela implementar estratégias para melhorar tanto sua eficiência (processo) quanto sua eficácia (objetivos). A ideia de competência pode ser entendida pela visão de Pinder (1984), que ressalta que a capacidade de um indivíduo para realizar uma tarefa é definida como habilidade, podendo também ser chamada de competência. A competência direciona o processo produtivo para o pleno atendimento de todos os objetivos relacionados à noção de eficiência.

Coates e McDermott (2002) definem competência como um conjunto de atitudes, habilidades e tecnologias que a empresa realiza melhor que seus concorrentes (diferenciação). No desenvolvimento de operações (sobretudo as mais complexas), é necessário habilidade para conseguir-se aumentar o desempenho da organização. Os desafios dos gestores envolvem, assim, identificar essas capacidades especiais dentro da empresa e entender como as competências podem vir a guiar atividades que deságuem em vantagem competitiva.

Essa breve revisão bibliográfica permite enfatizar um conceito de gestão estratégica associado a ações bem definidas. Observa-se, contudo, que nem sempre os autores de textos na área priorizam a estruturação de modelos práticos (estruturação das ações) para viabilizar o emprego das estratégias naturalmente associadas aos conceitos, sobretudo em termos da integração dessas ações, desenvolvidas em diferentes níveis da organização. Da mesma forma, ainda que se enfatize o papel da gestão da qualidade no comportamento estratégico das organizações, nem sempre se traduz essa preocupação em modelos que insiram a gestão da qualidade na gestão estratégica da empresa, único meio de se criar uma gestão estratégica da qualidade. 0 mesmo se pode dizer da gestão de processos. 0 presente trabalho propõe um modelo que tem por objetivo preencher essas lacunas observadas.

\section{Estrutura do modelo proposto}

O suporte teórico discutido abre espaço para uma proposta de aplicação prática bem caracterizada. A consistência dessa posição foi confirmada pelos trabalhos práticos descritos na introdução do texto.

Com base nesses elementos é que foi estruturado o modelo aqui proposto. Em linhas gerais, são sete suas fases: análise externa; definição de objetivos estratégicos; diagnóstico do processo produtivo; caracterização estratégica do processo produtivo; projeto do processo produtivo; gestão da operação do processo; e otimização do processo produtivo. Para cada fase foram fixados os objetivos gerais a atingir; focos de atuação (dependendo da natureza dessas metas, a fase pode ter um ou mais focos de atuação; se houver mais de um, as ações serão associadas a cada um deles); ações necessárias para viabilizar o alcance dos objetivos; resultados esperados; natureza dos indicadores para avaliar os resultados obtidos; associação dos indicadores selecionados naquela fase aos ambientes de produção da qualidade in-line, on-line, off-line, conforme as definições de Paladini (2004) e modelos de gestão (estratégica, tática e/ou operacional) adotados na fase em questão.

Uma visão geral do modelo é apresentada na Figura 1. Nela, observa-se que a gestão estratégica tem um curso mais amplo para caracterizar o crescimento da organização, quando comparada à gestão tática e operacional.

0 modelo possui sete fases, que podem ser agrupadas em dois conjuntos ou etapas. A primeira etapa reúne as análises preliminares, as definições e os diagnósticos. Envolve as três primeiras fases. Esta etapa é mostrada na Figura 2.

Já a segunda etapa envolve as decisões e os direcionamentos das ações propostas pelo modelo. Inclui as fases de 4 a 7 . Esta etapa é mostrada na Figura 3. A seguir, detalha-se o modelo. 


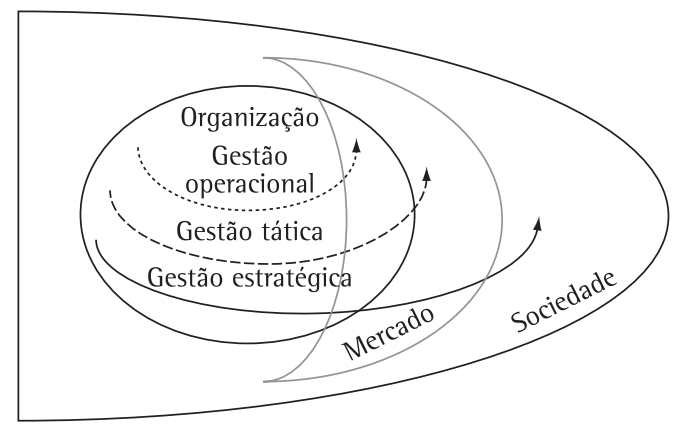

Figura 1. Crescimento da organização - visão estratégica.

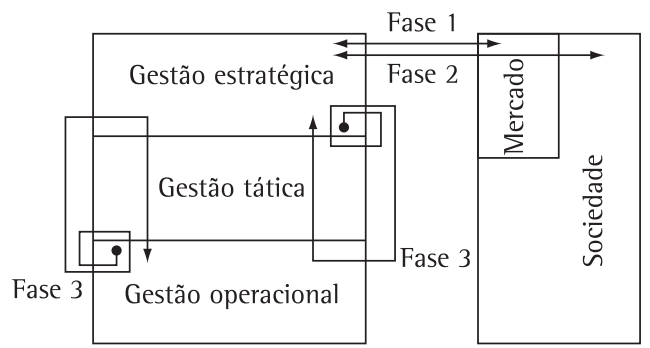

Figura 2. Etapa de análise, definições e diagnósticos (Fases 1 a 3).

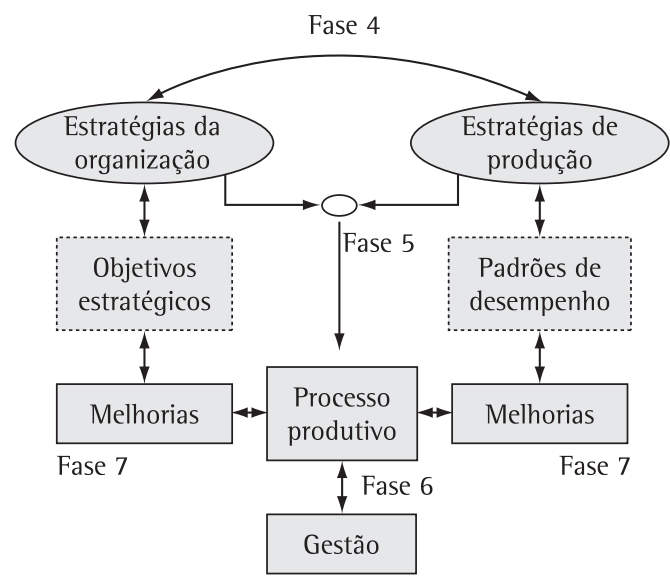

Figura 3. Etapas de decisões e direcionamentos.

\subsection{Fase 1 - Análise externa}

Aqui, pretende-se configurar com clareza o ambiente de atuação da organização. Para tanto, são propostas as seguintes ações: (1) definição das características que compõem uma visão abrangente do mercado e do ambiente geral de atuação da organização; (2) análise dinâmica dos cenários externos; (3) avaliação do atendimento ao mercado (em geral) e às necessidades específicas dos consumidores. São resultados esperados a definição das variáveis externas mais relevantes para a atuação da empresa; a fixação de padrões mais prováveis de desempenho para essas variáveis e a seleção de indicadores de monitoramento das variáveis. Os indicadores para avaliar os resultados obtidos são do tipo on-line e tem-se um modelo de gestão estratégica.

\subsection{Fase 2 - Definição de objetivos estratégicos}

Nesta fase, procura-se definir as características gerais da atuação da organização no mercado e na sociedade. Essas características envolvem dois focos de atuação: (1) relação da visão externa com o direcionamento das ações da organização (ação estratégica) e (2) desdobramentos no âmbito interno (gestão tática: potencialidades e competências; ações operacionais: processo produtivo). Para 0 primeiro foco, as ações propostas são: (1.1) definição da atuação da organização; (1.2) caracterização do foco como ação diferenciada de produto, serviço ou método; (1.3) estruturação do modelo competitivo da empresa - visão externa: ameaças e oportunidades; e (1.4) definição do perfil estratégico da organização diante dos diversos cenários de atuação. Para o segundo, (2.1) estruturação do modelo competitivo da empresa - visão interna: potencialidades e fragilidades da organização; (2.2) seleção do modelo de gestão adequado à concepção estratégica definida; (2.3) definição dos perfis de competências ajustados à concepção estratégica definida; (2.4) seleção das potencialidades requeridas para tanto e identificação das características gerais desejadas ou impostas ao processo produtivo como forma de atender ao modelo estratégico de ação selecionado.

Os resultados esperados envolvem 0 direcionamento de todas as ações da organização para a atuação no ambiente externo; estrutura organizacional, métodos de trabalho, produtos, serviços e meios definidos; diagnóstico de pontos fracos a minimizar e de pontos fortes a explorar; ações externas a desenvolver e opções a evitar na atuação da empresa; modelos de gestão tática e operacional adequados à concepção estratégica da organização. Os indicadores para avaliar os resultados obtidos são in-line (pontos fortes, pontos fracos, ajustes promovidos); off-line (potencialidades, deficiências e suporte requerido) e on-line (ameaças e oportunidades: concepção estratégica selecionada). E o modelo de gestão tem características operacionais e táticas (visão interna) e estratégicas (visão externa). 


\subsection{Fase 3 - Diagnóstico do processo produtivo}

Busca-se determinar as competências do processo produtivo. Há dois direcionamentos nesta fase: (1) gestão para avaliação de meios físicos e informações e (2) gestão para avaliação do potencial humano. Para o primeiro direcionamento, as ações propostas são: (1.1) a identificação das operações elementares do processo produtivo; (1.2) a caracterização de potencialidades e deficiências básicas das operações; (1.3) a definição de pontos críticos do processo (melhorias compulsórias requeridas); (1.4) a determinação de pontos deficientes do processo (melhorias desejáveis requeridas) e de pontos fortes que o caracterizam positivamente. Para o segundo direcionamento, tem-se: (2.1) o diagnóstico de aptidões; (2.2) a avaliação de habilidades; (2.3) a definição de carências em termos de habilidades e (2.4) a determinação de aptidões diferenciadas.

Os resultados esperados envolvem a determinação das melhores operações do processo que podem diferenciá-lo em relação aos concorrentes; a definição das operações de processo que requerem melhorias imediatas (compulsórias); a identificação das oportunidades de melhorias (desejáveis) e a estruturação do perfil das aptidões diferenciadas, instaladas e/ou disponíveis (competências distintas ou críticas). Os indicadores para avaliar os resultados obtidos são in-line (operações) e off-line (aptidões). E o modelo de gestão envolve aspectos operacionais (in-line) e táticos (off-line).

\subsection{Fase 4 - Caracterização estratégica do processo produtivo}

No âmbito do conceito das competências produtivas, pretende-se determinar o ajuste entre a estratégia da organização (ação determinada pelos objetivos estratégicos) e a estratégia da produção (padrões de desempenho das áreas operacionais e táticas). A fase envolve dois focos de atuação: (1) a gestão de operações e (2) a gestão do potencial humano. Para o primeiro caso, busca-se (1.1) avaliar as operações elementares de processo; (1.2) definir o padrão de flexibilidade das operações e as melhorias para atingir tais padrões; (1.3) consolidar pontos fortes do processo que são aderentes à ação estratégica e minimizar deficiências que comprometem essa mesma ação; (1.4) estruturar o programa básico de produção da qualidade e o programa de análise e incremento da produtividade; e (1.5) viabilizar o uso de ferramentas de amplo alcance, sempre visando a flexibilidade produtiva. Para o segundo foco, tem-se: (2.1) estruturação do modelo de gestão do potencial humano em acordo com as competências que lhe são inerentes; (2.2) criação do mapa das potencialidades (competências diferenciadas); (2.3) determinação de capacidades especiais para lidar com operações complexas e (2.4) seleção de competências particularizadas ajustadas à ação estratégica da empresa.

Como resultados esperados, quer se garantir que sejam identificadas e analisadas as operações de produção aderentes aos objetivos estratégicos da organização; estruturado o modelo de gestão dessas operações; viabilizado e consolidado o modelo de gestão do potencial humano com viés estratégico. Os indicadores para avaliar os resultados obtidos são in-line (operações) e off-line (recursos humanos), e o modelo de gestão contempla elementos operacionais (in-line), táticos (off-line) e estratégicos (desempenhos que atendem altos padrões).

\subsection{Fase 5 - Projeto do processo produtivo}

Aqui objetiva-se estruturar a estratégia de produção, que viabilizará as diretrizes gerais de operação do processo produtivo. Ações propostas: (1) análise e perfeita compreensão da estratégia da organização; (2) seleção das estratégias de negócio; (3) determinação de competências de produção requeridas pelas estratégias de negócios; (4) estruturação das estratégias de produção; (5) fixação dos níveis globais de eficiência do processo requeridos para o pleno alcance da estratégia da empresa; (6) definição dos mecanismos de integração dos meios (eficiência como padrão de processo e eficácia como alcance de objetivos); (7) fixação dos níveis globais de eficácia a partir da ação estratégica da organização e dos níveis de eficiência obtidos e (8) estruturação do modelo gerencial do processo produtivo. A quarta ação foi bem detalhada, sendo dividida em quatro outras ações: (4.1) adequação do processo à missão da empresa; (4.2) determinação de objetivos compatíveis com a missão estabelecida; (4.3) determinação das políticas operacionais (diretrizes gerais de operação) e (4.4) ações de produção (viabilização da estratégia de produção). Para este último caso, pretende-se definir o nível de desempenho das operações de processo e do suporte ao processo, incluindo a ação do potencial humano no nível operacional.

Alguns resultados esperados: definição de um modelo de estratégia de produção adequado à estratégia da organização; seleção de ações de produção direcionadas para elevados níveis de 
eficiência e realização de investimentos em eficiência para utilizá-la como componente da eficácia. Os indicadores para avaliar os resultados obtidos são on-line (estratégia da empresa); in-line (operações e meios que integram a estratégia de produção); off-line (integração de recursos), e o modelo de gestão possui componentes operacionais (in-line), táticos (off-line) e estratégicos (on-line).

\subsection{Fase 6 - Gestão da operação do processo}

Esta fase visa criar o modelo de gestão para garantir o correto desenvolvimento do processo produtivo. Mais em geral, trata-se do gerenciamento do processo de produção para alinhá-lo aos objetivos estratégicos da organização. E envolve três focos de atuação: (1) gestão de meios, recursos físicos e informações; (2) gestão das contribuições individuais e (3) gestão por equipes. Ações para cada foco de atuação: Para o primeiro: (1.1) criação de um modelo de gestão que privilegie a integração de meios; (1.2) estruturação de equipes operacionais que atuem em conjunto nas ações de processo; (1.3) investimento contínuo na flexibilização das operações de processo (interação entre os meios e as pessoas). Para o segundo: (2.1) investimentos no desenvolvimento de aptidões particularizadas (definidas na fase 3); (2.2) desenvolvimento do processo de gestão de contribuições individuais; (2.3) avaliação do grau de competência dos colaboradores; (2.4) criação do modelo de gestão de habilidades; (2.5) estruturação do processo de formação; (2.6) desenvolvimento do processo de formação; (2.7) avaliação do processo de formação; (2.8) estruturação do processo de qualificação; (2.9) desenvolvimento e avaliação do processo de qualificação; (2.10) determinação de habilidades diferenciadas; (2.11) estruturação, desenvolvimento e avaliação do processo de atualização permanente; e (2.12) investimentos no desenvolvimento de competências particularizadas. Já para o terceiro, tem-se: (3.1) desenvolvimento do processo de gestão de contribuições coletivas; (3.2) estruturação de modelos de gestão participativa; (3.3) levantamento de redes formais e informais de interatividade entre pessoas e áreas; (3.4) avaliação da capacidade dos colaboradores de trabalhar em grupo; (3.5) definição de um processo de preparo para o trabalho em equipe: dinâmica de grupo; (3.6) atividades de grupos: atribuição de ações e responsabilidades; fixação de metas de eficiência a atingir; ampliação da área de atuação (área externa à organização) e fixação de metas de eficácia a atingir.
Os resultados esperados envolvem definições consolidadas: estrutura de um modelo de gestão que investe na integração dos meios como pré-requisito para a agilização das operações de processo; equipes multidisciplinares que atuam em um modelo de gerenciamento integrado das operações de produção; atividades de produção flexíveis e adequadas ao movimento de alteração e adaptação de objetivos operacionais; pessoal formado, habilitado, qualificado e atualizado; modelos quantitativos de avaliação do desempenho do potencial humano da organização; modelo de gestão que ajusta competências disponíveis aos objetivos estratégicos da empresa; modelo de gestão participativa, que prioriza contribuições coletivas a partir de potencialidades individuais; modelo de avaliação quantitativa dos níveis de eficiência e eficácia da organização. Os indicadores para avaliar os resultados obtidos são melhorias em ambientes in-line (eficiência); melhoria em ambientes on-line (eficácia) e melhoria em ambientes off-line (integração). Ainda envolvem a avaliação das melhorias nas ações do potencial humano nos três ambientes via modelos quantitativos, mas com ênfase no ambiente off-line, e do processo gerencial (igualmente ambiente off-line). 0 modelo de gestão contempla ações nos ambientes operacionais (in-line), táticos (off-line) e estratégicos (on-line).

\subsection{Fase 7 - Otimização do processo produtivo}

Esta fase busca promover a melhoria contínua do processo produtivo e seu crescente ajuste em relação aos objetivos estratégicos da organização. A fase inclui (1) monitoramento do cenário externo à empresa; (2) avaliação periódica do processo; (3) verificação dos níveis de atuação da organização no ambiente em que ela se insere e (4) capacidade de contínuo ajuste da empresa à realidade do mercado e da sociedade. São quatro os focos de atuação: (1) cenário externo à organização; (2) avaliação periódica do processo; (3) níveis de atuação externa da empresa e (4) ajuste da organização à realidade do mercado e da sociedade como um todo. Ações para cada foco de atuação :

- Monitoramentos de cenários externos: visão temporal (momento) das variáveis externas à organização e relevantes à sua atuação, e visão sequencial (histórico e tendências) dessas mesmas variáveis.

- Desenvolvimento de um modelo de avaliação periódica do processo: avaliação da contribuição do processo produtivo para o desempenho da organização e para o alcance de objetivos estratégicos da empresa; determinação de 
elementos que tendem a diferenciar o processo produtivo em relação a concorrentes; revisão dos indicadores de competitividade da organização; avaliação do processo de integração de meios em termos da agilidade e da flexibilidade conferidas às operações de produção; análise da melhoria no desempenho das operações e análise da melhoria das operações integradas.

- Avaliação da ação da empresa no ambiente em que ela se insere: determinação de indicadores para avaliar a presença da organização no cenário externo; análise permanente de novos caminhos para responder rapidamente às mudanças de mercado e da sociedade e avaliação dos indicadores da empresa em confronto com indicadores obtidos em outras empresas (no caso, as concorrentes).

- Avaliação do ajuste do processo produtivo e da organização como um todo às características da demanda: avaliação do ajuste entre a estratégia da organização e a estrutura da produção (ou seja: a adequação do processo produtivo aos objetivos estratégicos); análise da visão da eficiência como valor para a eficácia; determinação de indicadores da interação efetiva entre os objetivos estratégicos e as prioridades associadas às operações produtivas (direcionamento do processo produtivo para atendimento de objetivos estratégicos); determinação de indicadores externos para avaliar o ajuste das operações das organizações aos requisitos do mercado e avaliação do comprometimento social da empresa.

Como resultados esperados da fase, listam-se: perfeita e rápida compreensão do cenário externo à organização, sua situação atual, tendências imediatas e de longo prazo; permanente avaliação do processo produtivo de forma a garantir sua crescente contribuição para o alcance de objetivos estratégicos da empresa; melhoria contínua na atuação da organização no ambiente em que ela se insere, sobretudo nas faixas de mercado atendidas; ampliação permanente da capacidade de ajuste à realidade do mercado; níveis de expectativa da demanda atendidos e superados; imagem social positiva consolidada. Os indicadores para avaliar os resultados obtidos são on-line: avaliação do cenário externo à empresa e ajuste à realidade do mercado; in-line: avaliação periódica do processo; in-line e on-line: níveis de atuação da organização no ambiente externo e off-line: comprometimento social da empresa. Tem-se, aqui, a gestão operacional (in-line), tática (off-line) e estratégica (on-line).

\section{Aplicação prática do modelo proposto}

0 modelo proposto foi implantado ao longo do desenvolvimento de um processo de gestão estratégica em uma organização produtora de bens. A interação dos autores com essa empresa começou em final de 2006 e se desenvolveu sob forma de ações acadêmicas (orientação de trabalhos de conclusão de cursos de especialização desenvolvidos por alunos que eram funcionários da empresa e de estagiários de graduação que lá atuavam) e técnicas (apoio às empresas de consultoria contratadas pela organização). Assim, a observação direta e o acompanhamento de ações de melhoria, desde sua concepção, foram duas das formas mais usuais de obtenção de dados. Os representantes da empresa com as quais os contatos eram mais frequentes eram membros da média gerência e dois diretores (área industrial e planejamento estratégico). A coleta de dados cobre o período de janeiro de 2007 a dezembro de 2008, quando ocorreram as ações mencionadas. As fontes dos dados consistiam de documentos da própria organização, e sua análise seguia o processo usual de avaliação de melhorias.

A empresa estudada é uma organização industrial que produz bolachas e biscoitos, sendo sua sede situada no interior do Estado de São Paulo, onde está sua maior fábrica. A empresa congrega mais quatro fábricas, situadas em outros estados. Tendo em vista a natureza das informações aqui consideradas e suas implicações no perfil estratégico da própria empresa, assumiu-se o compromisso com a empresa de que seu nome, razão social ou outras informações que pudessem identificá-la, ou a algum de seus produtos, não seriam aqui incluídos. 0 Quadro 1 mostra, esquematicamente, o desenvolvimento descrito a seguir.

\subsection{Situação anterior}

A organização sempre priorizou uma linha de produtos constituída por biscoitos amanteigados (biscoito doce com sabor de manteiga), por ser esse seu histórico carro-chefe das vendas. Além disso, investe esforços nas linhas de biscoitos de milho (biscoito doce), nas broas (biscoito doce, com fécula de mandioca, açúcar, clara de ovos e bicarbonato de amônio), nos biscoitos à base de polvilho comum (também biscoito doce) e de polvilho especial (esse biscoito é salgado, e inclui em sua composição o polvilho azedo). Outras linhas de produtos incluem os merengues (feitos com açúcar refinado e claras de ovos), biscoitos que apresentam sabor característico mais forte e acentuado, como aqueles à base de amendoim, mel e glaceados em geral, e ainda produtos tipo "folhado" (biscoito doce com cobertura de açúcar). 
Quadro 1. Fluxo de ações no estudo de caso.

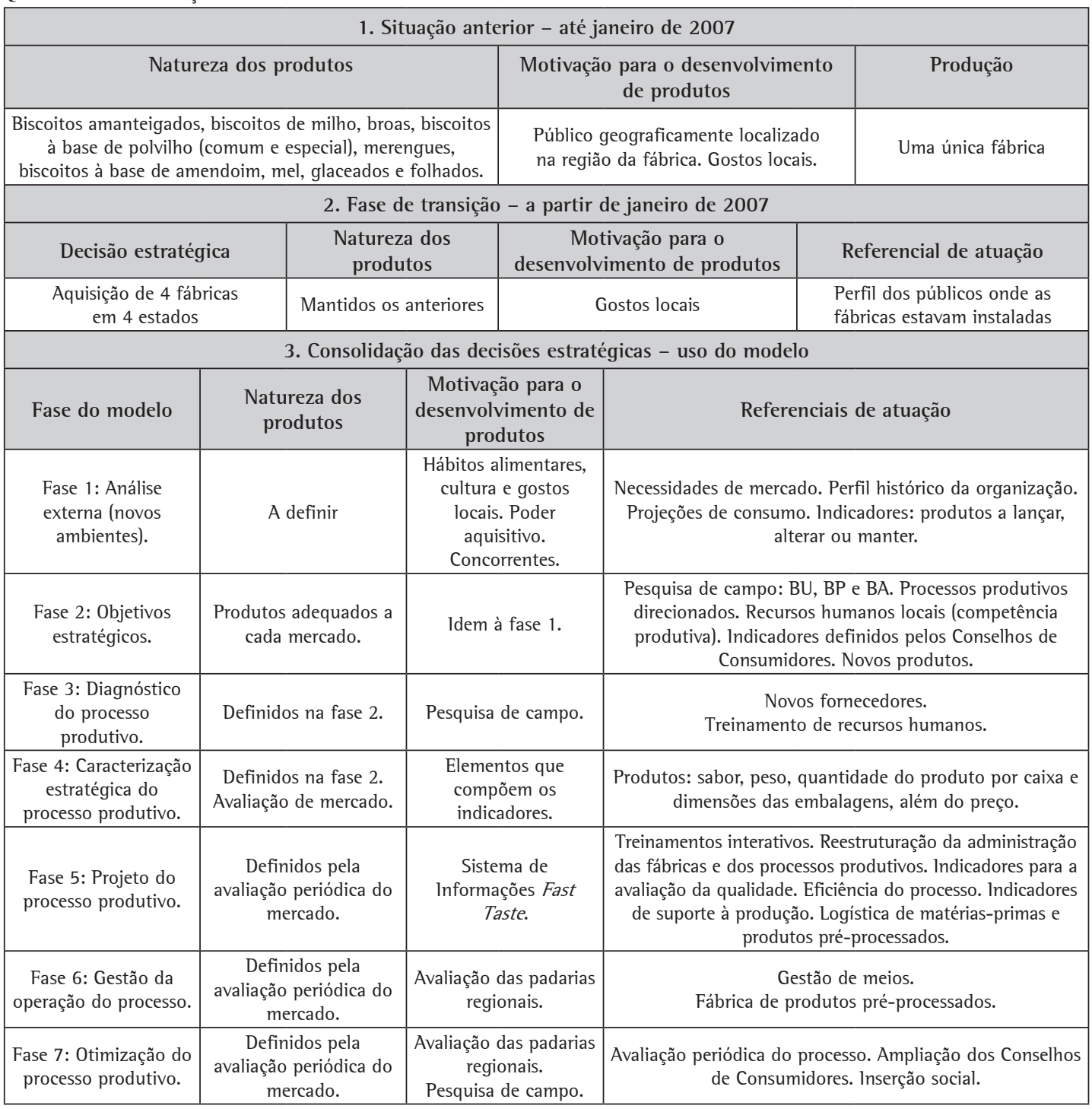

\subsection{Fase de transição}

Historicamente, sua produção começou na fábrica do interior de São Paulo e, por isso, sua linha de produtos sempre foi voltada para um público localizado nessa região. Os bons resultados obtidos pela empresa ao longo dos dez primeiros anos de funcionamento a levaram a optar por voos mais altos. Em 2006, a empresa resolveu ampliar seu raio de atuação e tomou uma decisão estratégica bem específica: ao invés de investir em processos logísticos, por exemplo, e ampliar mercados a partir de uma mesma base, decidiu adquirir fábricas em quatro estados. 0 suporte à decisão estratégica estava associado à proposta de manufaturar produtos de acordo com o perfil do público-alvo de cada uma dessas regiões, que certamente poderia não ser o mesmo perfil do público original, radicado no interior paulista.

\subsection{Consolidação das decisões estratégicas - Uso do modelo}

A organização iniciou o processo de ampliação adotando a fase 1 do modelo (análise externa), tentando configurar com clareza os quatro novos ambientes de atuação, ou seja, as regiões geográficas selecionadas a partir das fábricas adquiridas. Em termos de visão de mercado, foram considerados hábitos alimentares locais (formatação das refeições), traços culturais (por exemplo, o hábito de tomar café em finais de tarde, cujo acompanhamento não 
é o mesmo do café da manhã), gostos locais por determinados alimentos (prioridade aos derivados do leite; tipos de frutas mais comuns; uso de cafés mais ou menos encorpados etc.) e também itens como poder aquisitivo, existência de concorrentes locais ou provenientes de outras regiões (mas com atuação na área). Definiu-se um modelo de atendimento que poderia vir a ser desenvolvido tanto em termos do mercado como um todo como de necessidades mais específicas (maior preferência por produtos doces ou salgados, por exemplo). Esses elementos foram confrontados com a atuação histórica da organização. A seguir, foram feitas projeções de consumo para períodos próximos e outros, mais a longo prazo.

Dessa análise surgiram os indicadores on-line que definiram quais produtos das fábricas adquiridas deveriam ser mantidos, quais seriam alterados e quais deveriam ser lançados (preferências dos consumidores).

Quase simultaneamente à fase 1, começou a fase 2 do modelo (definição de objetivos estratégicos). A organização entendeu que as características de atuação deveriam ser pautadas pela seleção de produtos adequados a cada mercado. Foi feita, então, uma pesquisa de campo que permitiu que a empresa definisse três grupos de produtos. 0 primeiro grupo, que ficou conhecido como BU, inclui biscoitos e bolachas com aceitação em todo o mercado atendido pela empresa. 0 segundo, chamado BP, define uma relação direta entre cada tipo de biscoito ou bolacha e uma área geográfica de maior consumo. 0 terceiro grupo, denominado BA, constitui-se de biscoitos e bolachas vendidos em todas as regiões de atuação da empresa, mas que requerem adaptações específicas para cada caso, sobretudo em termos da inserção de maiores percentuais de determinados ingredientes (açúcar ou farinha de nozes, por exemplo).

Essa decisão (estratégica) de agrupar os produtos exigiu alguns desdobramentos nos ambientes tático e operacional (processo produtivo). No primeiro caso, foram definidas as potencialidades e as competências necessárias para formatar os produtos do grupo BP e para processar os ajustes do grupo BA. A organização decidiu, então, selecionar recursos humanos locais, ou seja, padeiros, confeitadeiras e doceiras residentes em cada uma das regiões atendidas, de modo que fosse possivel conferir um "sabor local" aos biscoitos e bolachas. Esse grupo de profissionais compôs a capacidade local de operação, plenamente direcionada para 0 mercado até por força de sua origem (competência produtiva).

0 efeito dessa estratégia foi imediato. Os produtos passaram a ter plena identificação regional e, por isso, diferenciaram-se em relação aos produtos "massificados" dos concorrentes. Essa estratégia foi convertida em um conjunto de peças publicitárias de inegável apelo junto aos consumidores.

Ainda na fase 2 , ao analisar os indicadores in-line do processo, a organização entendeu que tinha alguma dificuldade em criar plena adaptação dos produtos ao mercado, embora a mão de obra local contribuísse muito para tanto. Assim, decidiu criar os Conselhos de Consumidores. A ideia era simples. Por meio de exposição em supermercados, participação em eventos (nos quais servia gratuitamente os coffee-breaks), ações interativas em pontos de vendas, distribuição de "amostras grátis" dos produtos em escolas e associações comunitárias, a empresa começou a captar as opiniões dos consumidores sobre cada produto e a fazer pequenas modificações na receita (indicadores in-line), sempre com base na opinião dos consumidores (indicadores on-line).

Uma das primeiras propostas dos Conselhos dos Consumidores foi a introdução de novos produtos, que até então a empresa não fabricava. Dois deles se revelaram campeões de vendas: dois tipos de biscoitos de chocolate, com cobertura de chocolate ao leite, o primeiro com recheio de baunilha e o segundo com recheio de morango. Até o peso da embalagem (125 g) foi sugestão de um dos conselhos.

Estava sendo iniciada a fase 3 do modelo, na qual a empresa redefiniu seus fornecedores em face das novas receitas adotadas para biscoitos e bolachas e determinou que todos os recursos humanos da organização passassem por um treinamento, para adequar os indicadores in-line do processo produtivo às informações vindas dos Conselhos de Consumidores (indicadores on-line). Nesse momento, a empresa determinou outras variáveis relevantes para os produtos, em face tanto das características do processo produtivo em si (já agora migrando para a fase 4 do modelo) quanto das expectativas de consumo. Aqui, foram definidos os conjuntos gerais de indicadores in-line, on-line e off-line, ficando eles associados a quatro grupos de atributos: (1) sabor (ingredientes e forma de prepará-los), (2) embalagem (peso), (3) quantidade do produto por caixa e (4) dimensões das embalagens. Um quinto elemento, preço, não foi definido como grupo independente, mas foi associado a cada um dos quatro grupos de atributos, conforme as posições dos Conselhos de Consumidores.

As providências anteriores determinaram um novo projeto para o processo produtivo, já agora na fase 5 do modelo. As ações mais importantes desta fase foram as seguintes: 
- Estruturação de um novo sistema de informações para a organização, totalmente automatizado, batizado como Fast Taste. Ainda que sua estrutura seja relativamente complexa (e por isso não será aqui detalhada), a ideia que pautou sua criação é simples: fazer as informações dos Conselhos dos Consumidores chegarem rapidamente às fábricas, de forma a processar, no menor espaço de tempo possível, as alterações no grupo BA e o lançamento de novos produtos para o grupo BP. Essas informações afetam também o grupo BU, não tanto em termos do primeiro, mas sim dos outros três atributos.

- Desenvolvimento de treinamentos interativos, colocando os profissionais que atuam no projeto dos produtos (grupos BP e BA) em contato com os Conselhos de Consumidores. Integram o treinamento as sessões de degustação de novos produtos (ou de produtos “adaptados"). Essas sessões foram criadas na fase 2 , mas se consolidaram neste momento.

- Reestruturação da administração das fábricas, que se tornam mais independentes e com viés mais local.

- Criação de um modelo de avaliação da qualidade baseado em indicadores on-line em níveis locais (fábricas) e, a seguir, em níveis mais amplos (toda a organização).

- Criação de indicadores in-line para avaliar níveis locais e globais de eficiência do processo. A ideia foi transformar ações quase artesanais de produção em processos industriais.

- Avaliação dos indicadores off-line da organização e das fábricas em particular, para garantir adequado suporte às ações de produção.

- Criação de um modelo de logística (até então, apenas incipiente, até por força da decisão de descentralizar a produção) em termos de matériasprimas e produtos pré-processados (no caso do grupo BU) e da distribuição dos produtos acabados.

Por envolver a gestão dos processos, essas atividades inauguraram a fase 6 do modelo, situação atual da empresa. Um processo de consultoria está propondo, agora, um novo modelo de gestão de meios, que pode determinar a construção de uma sexta fábrica, situada em um ponto intermediário entre as cinco atuais, de forma a gerar produtos pré-processados para os grupos BU e BA. No caso do grupo BU, o acabamento a ser feito posteriormente envolve os atributos 2 a 4; no segundo caso, trata-se especificamente do atributo 1 (sabor).

Outra decisão que está sendo implementada é a aquisição de 12 padarias nas regiões onde as fábricas estão instaladas. A meta é desenvolver produtos de forma experimental nesses locais. Por sua proximidade com o público consumidor, elas permitem a rápida avaliação de indicadores on-line. Assim, a produção em escala industrial seria respaldada por uma pesquisa de campo mais efetiva, desenvolvida em níveis locais pelas padarias.

Associando a gestão das equipes (fase 6) com a preocupação com a otimização do processo produtivo (fase 7), a empresa iniciou em dezembro de 2008 a implementação de um modelo de avaliação periódica do processo. Esse modelo é composto por indicadores de aceitação do produto, que são monitorados em diferentes períodos de tempo. Para garantir um acompanhamento adequado do cenário externo à organização, a empresa decidiu ampliar os Conselhos de Consumidores, promovendo visitas organizadas às fábricas, criando as Semanas da Merenda Escolar Patrocinada (em escolas e também em universidades) e instituindo prêmios para sugestões de melhorias nos produtos feitas por consumidores. De outra parte, a empresa está investindo em um programa de inserção social, patrocinando a realização de Cafés da Manhã Comunitários em asilos, creches e outras associações beneficentes.

Os resultados da adoção desse modelo são visíveis em termos de aumento de faturamento e de lucratividade, aquisição de faixas expressivas de mercado, fixação das marcas de biscoitos e bolachas nas regiões atendidas e a disponibilidade de recursos (próprios) para novos investimentos. Cláusulas contratuais com o grupo consultor impedem que sejam revelados números precisos sobre esses resultados. Mas pode-se ter uma ideia em termos de valores percentuais: entre 2007 e 2009, na fábrica original, a marca mais vendida teve um aumento de 34,5\% em unidades comercializadas; o valor médio de aumento de vendas, para esta fábrica, foi de 64,5\%. 0 faturamento médio mensal do grupo, com as novas fábricas e o aumento de vendas, cresceu $275 \%$ nestes dois anos. 0 nível de endividamento (por força da aquisição das novas unidades em 2007) já caiu 25\%. Nas áreas onde as fábricas foram adquiridas, a empresa tem hoje cerca de 35\% do mercado (contra zero em 2007). E já tem a liderança de vendas em um tipo de biscoito. Três padarias vão transformar-se em supermercados ao longo do corrente ano, com recursos próprios da empresa. Também a construção da sexta fábrica ocorrerá com recursos próprios. Observa-se, pelo volume de vendas, que a empresa não foi diretamente afetada pela crise econômica recente, apesar do aumento de preços de matérias primas. 


\section{Conclusões}

Inicialmente, conclui-se que existe uma diferença bem caracterizada entre ação estratégica e decisão estratégica. De fato, existem modelos de gestão estratégica com base em ações operacionais, táticas e mesmo estratégicas, como se viu. É difícil uma organização atuar estrategicamente com base apenas em seus processos produtivos, ou somente ancorada no modelo gerencial ou, ainda, priorizando exclusivamente a contínua inovação da embalagem de seus produtos. Diferentes fatores determinam a priorização de uma dessas ações, mas sempre em conjunto com as demais. Daí a necessidade, a conveniência, a utilidade e a oportunidade do modelo proposto, que busca criar mecanismos interativos entre os três conjuntos de ações. Como se observa (inclusive no caso prático relatado) o modelo estratégico tende a se consolidar à medida que as decisões estratégicas são estruturadas a partir das competências produtivas: o modelo propõe que tais competências sejam direcionadas para consolidar a atuação da organização no mercado e na sociedade.

Outra conclusão relevante diz respeito ao emprego efetivo do conceito de competências produtivas para caracterizar ações estratégicas e agregá-las ao processo de tomada de decisões estratégicas da empresa. Evidentemente, esta não é a única forma de construir-se um processo de gestão estratégica e, por isso, foi ressaltado que se trata de uma delimitação importante do presente trabalho.

Em geral, observa-se que pode ser construído um link robusto entre competências produtivas, estratégias de produção e estratégias de negócios, formalizando assim as diretrizes que guiam o processo produtivo, de forma que produtos, métodos de produção e serviços gerem vantagens competitivas essenciais à sobrevivência das organizações. Nota-se, portanto, que as competências produtivas requerem um modelo de integração entre as estratégias de negócios e as operações em relação ao ambiente em que a organização se insere (mercado e sociedade). 0 modelo proposto prioriza essa exigência.

0 modelo proposto tende a minimizar um problema percebido com certa frequência nos processos gerenciais das organizações: o fato de que se tem negligenciado o papel dos gestores na formulação e na implementação de ações produtivas com viés estratégico. A alta administração das organizaçõesé, em última análise, a maior responsável pela interação entre os setores da empresa (elos internos) e pela integração da própria empresa com o ambiente (elos externos). A falta da estruturação clara desses elos tem consequências críticas em todas as variáveis relevantes nas diferentes formas de atuação da empresa (porte, estrutura, sistema de planejamento estratégico, recursos e informações, recursos humanos etc.).

Essa conclusão tem por base o suporte prático do trabalho, que envolve tanto as organizações nas quais estudos preliminares nessa área foram feitos quanto a organização onde o modelo foi experimentalmente aplicado. Esta, na verdade, também é uma delimitação importante do trabalho: tanto a proposta de solução para o problema aqui estudado quanto a própria aplicação prática dessa solução sofrem o impacto da realidade considerada apenas uma amostra do conjunto das organizações produtivas.

0 suporte teórico mostra que há variadas interpretações e distintos enfoques possíveis para os conceitos de gestão estratégica ou mesmo para a gestão da qualidade. De modo geral, foram aplicações práticas específicas que acabaram por determinar essas análises. Entretanto, mesmo com esse viés, abordagens e enfoques nem sempre determinam métodos e processos de uso das estratégias que os conceitos parecem sugerir ou definir. lgualmente parecem faltar ações efetivas que insiram a gestão da qualidade na gestão estratégica, de forma que nem sempre se atinge o esboço próprio da gestão estratégica da qualidade. Assim, o modelo proposto foi desenvolvido com o propósito de minimizar essa constatação. Tanto em termos conceituais quanto práticos. E isso ficou evidente no caso estudado. A noção de competências produtivas mostrou-se adequada para as características gerais do modelo proposto; a aplicação prática evidencia que 0 modelo é viável e atende o que dele se espera.

Há, neste momento, outras aplicações práticas do modelo proposto em andamento. Essas ações permitirão refinar seus focos de atuação e suas ações. Mas o que se observa, confirmando o que a aplicação prática aqui descrita evidencia, é que sua estrutura geral é adequada ao que se propõe. $\mathrm{Ou}$ seja: novas implementações permitirão melhorias pontuais, já que suas características, assim como sua estrutura, não parecem requerer alterações.

\section{Referências}

ACKOFF, R. Planejamento empresarial. Rio de Janeiro: LTC, 1978.

ALBRECHT, K. Radar corporativo: como entender os cenários que estarão regendo o futuro de seus negócios. São Paulo: Makron Books, 2001.

ANSOFF, H.; MCDONNEL, E. Implantando a administração estratégica. São Paulo: Atlas, 2004.

BECTON, J. B.; SCHRAEDER, M. Strategic human: resources management: are we there yet? Journal for Quality and Participation, v. 31, n. 4, p. 11-18, 2009. 
BEECROFT, G. The role of quality in strategic management. Management Decision, v. 37, n. 6, p. 49-50, 1999.

BELL, J. Projeto de pesquisa: guia para pesquisadores iniciantes em educação, saúde e ciências sociais. 4. ed. Porto Alegre: Artmed, 2008.

BORNHOLDT, W. Orquestrando empresas vencedoras: guia prático da administração de estratégias e mudanças. Rio de Janeiro: Campus, 1997.

CHOE, K.; BOOTH, D.; HU, M. Production competence and its impact on business performance. Journal of Manufacturing Systems, v. 16, n. 8, p. 409-421, 1997.

CLAVEL, J. A Arte da Guerra - Sun Tzu. Rio de Janeiro: Record, 2000.

COATES, T. T.; McDERMOTT, C. M. An exploratory analysis of new competencies: a resource based view perspective. Journal of Operations Management, v. 20, n. 5, p. 435-450, 2002.

DEGEN, R. J. O empreendedor. Rio de Janeiro: McGraw-Hill, 1999.

DEW, J. R. Developing a quality-centered strategic plan. Quality Digest, p. 49-52, 2008.

DIXIT, A. K.; NAlEBUFF, B. J. Pensando estrategicamente. São Paulo: Atlas, 2006.

FISHMANN, A.; ALMEIDA, M. Planejamento estratégico na prática. São Paulo: Atlas, 1990.

GAJ, L. $O$ estrategista: do pensamento a ação estratégica na organização. São Paulo: Makron, 2002.

GALBRAITH, J. R.; LAWLER 111, E. E. Organizando para competir no futuro: estratégia para gerenciar o futuro das organizações. São Paulo: Makron Books, 2001.

GIBSON, R. Repensando o futuro. São Paulo: Makron Books, 2005.

GlL, A. C. Como elaborar projetos de pesquisa. 4. ed. São Paulo: Atlas, 2002.

GlL, A. C. Métodos e técnicas de pesquisa social. São Paulo: Atlas, 1999.

GUIMARÃES, T.; STAPLES, D. S.; MCKEEN, J. Assessing the impact from information systems quality. Quality Management Journal, v. 14, n. 1, p. 30-44, 2007.

HAMELL, G.; PRAHALAD, C. K. Competindo pelo futuro: estratégias inovadoras para obter o controle do seu setor e criar os mercados de amanhã. Rio de Janeiro: Campus, 1995.

JOHANNSEN, C. G. Strategic issues in quality management: theoretical considerations. Journal of Information Science, v. 22, n. 3, p. 155-164, 1996.

KETTUNEN, J. Integration of strategic management and quality assurance. Turku: Turku University of Applied Sciences Press, 2008.
LAKATOS, E. M.; MARCONI, M. A. Metodologia do trabalho científico. São Paulo: Atlas, 1993.

MADU, C. N.; KUEl, C. H. Strategic total quality management. Santa Barbara: Quorum Books, 2008.

MARCIAL, E. C.; GRUMBACH, R. J. S. Cenários prospectivos: como construir um futuro melhor. São Paulo: FVG, 2002.

MARKIDES, C.; CUSUMANO, M. Pensamento estratégico. São Paulo: Campus, 2002.

MARQUES, J. Spirituality at work: internal growth with potential external challenges. Journal for Quality and participation, v. 31, n. 3, p. 81-91, 2008.

MENEZES, E. M.; SILVA, E. L. Metodologia da pesquisa e elaboração de dissertação. Florianópolis: Editora da UFSC, 2005.

NICHOLS, M. D.; HOURY, K. Adapting to troubled times. Quality progress, p. 8-9, 2009.

PAGNONCELLI, D.; VASCONCELlOS FILHO, P. Construindo estratégias para vencer! Rio de Janeiro: Campus, 2001.

PALADINI, E. P. Avaliação estratégica da qualidade. São Paulo: Atlas, 2004.

PINAR, M.; OZGUR, C. The long-term impact of 1509000 certification on business performance. Quality Management Journal, v. 14, n. 4, p. 21-41, 2007.

PINDER, C. C. Work motivation: theory, issues, and applications. Glenview: Scott Foresman Co., 1984.

PORTER, M. Estratégia competitiva. Rio de Janeiro: Campus, 1991.

PORTER, M. Vantagem competitiva das nações. Rio de Janeiro: Campus, 1993.

SCHMENNER, W.; VASTAG, G. Revisiting the theory of production competence: extensions and cross-validations. Journal of Operations Management, v. 24, n. 6, p. 893-909, 2006.

SRINIDHI, B. Strategic quality management. International Journal of Quality Science, v. 3, n. 1, p. 38-70, 1998.

STAHL, M.; GRIGSBY, D. W. Strategic management: total quality and global competition. New York: Blackwell Business, 2007.

TELLIS, G. J.; GOLDER, P. N. Ação e visão. Rio de Janeiro: Campus, 2002.

VICKERY, S. K. A theory of production competence revisited. Decision sciences, v. 22, n. 3, p. 635-643, 1990.

VICKERY, S.; DROGE, C.; MARKLAND, R. Production competence and business strategy: do they affect business performance? Decisions Sciences, v. 24, n. 2, p. 435-456, 1993.

WIRTZ, B. W.; MATHIEU, A.; SCHILKE, O. Strategy in high-velocity environments. Long Range Planning, v. 40, n. 3, p. 295-313, 2007.

\title{
Production competence and strategic vision: an interactive management model
}

\begin{abstract}
Considering the conceptual distinction between strategic decisions and strategic actions and using production competence definitions, a general model is presented here. This model creates an interactive structure to aggregate the elements that compose the competitive differential of the organization. The objective of the structure is to define the way that organizations can act in the market, and, in general, in the whole society. To develop the model, a theoretical support structure has been defined in terms of concepts, positions and arguments related to Strategic Management, according to its different approaches. The model is now being used by an industrial organization and its basic phases have been used in the definition of the strategic behavior of the organization in question over the last two years. The conceptual analysis and the practical observations that have come from the effective implementation of the model have allowed us to propose some general and specific conclusions here.
\end{abstract}

\section{Keywords}

Production competence. Strategic vision. Interactive management. 